\title{
SUTURA INTRADÉRMICA NA CIRURGIA DOS PEQUENOS ANIMAIS
}

\author{
(SUBCUTICUIAR SUTURE IN THE SURGERY OF SMALI, ANIMALS)
}

\author{
Firnesto Antonio Matera \\ I.ivre Docente \\ Angelo V. Stopiclia \\ Veterinário Interno \\ 4 estampas (4 figuras)
}

No fechamento da ferida operatória o cirurgião deverá restabelecer do melhor modo a constituição anatômica e a função dos órgãos, artificial e temporàriamente divididos. Com o progresso da cirurgia, sobretudo após o advento da assepsia e da antissepsia, os cirurgióes se preocuparam em reduzir ao minimo as complicaçôes post-operatórias produzidas por deficiências da sintese dos tecidos. Atualmente, realizar uma operação deixando cicatriz perfeita é o ideal em cirurgia, merecendo destarte grande importância o capítulo que estuda a síntese da pele.

O cirurgião, ao executar uma operação, deve forçosamente abrir passagem através dos tecidos, resultando disso uma cicatriz permanente na pele, sinal indelével da operação.

\section{SINTESE DA PELE}

Na sintese da pele podemos usar grampos ou fios.

E' muito corrente o emprêgo dos grampos de pressão ("serres-fines") ou dos grampos de Michel ("agrafes").

Os inconvenientes apresentados pelos "serres-fines" seja pela dificuldade na aplicação do penso curativo, seja pela dor contínua que produzem, determinaram seu abandono.

OS defensores do emprêgo das "agrafes" baseiam seus argumentos no fato de elas nũo determinarem lesões da camada basal da epiderme, o que é muito importante para o processo cicatricial. Isto, todavia, só acontece, segundo MoNTEIro, quando não se apertam muito os grampos, pois, no caso contrário, chegam até a determinar pequenas áreas de isquemia e destruição da pele. A rapidez de sua colocação é talvez o maior argumento para a predileção pelo seu

- Trabalho apresentado ao $\mathrm{V}$ Congresso Brasileira de Medicina Veterinária, realizado em São Paulo, de 28-8 a 3-9-1950. 
uso, porém, em cirurgia veterinária, êsse processo, a nosso ver, apresenta alguns inconvenientes, que passamos a examinar: se forem pouco apertadas, soltam com facilidade; se muito apertadas, podem perfurar a pele e revirar-se, irritando as camadas mais profundas e, por conseguinte, dificultar a cicatrização "per primam", dando lugar a outra mais grosseira. Não permilem coaptação anatômica perfeita dos lábios da ferida. A retirada feita no mínimo sete dias após a aplicação não é simples, determinando reaçôes bruscas do animal pela dor que provoca. O material de sua fabricação varia conforme a procedência, e seu custo é relativamente elevado.

Em conclusão, êsses fatôres não as recomendam como processo ideal de sín. tese da pele.

Os fios utilizados para síntese da pele são de material inabsorvivel (crina, linho, sêda e algodão). Existem três tipos de suturas: contínua (serzidura), de pontos separados (simples, em "U", de Donati, com placas, botões ou pérolas), e intradérmica; esta última será o objeto de estudo do presente trabalho.

\section{SUTURA INTRADERRICA}

Christmann, Ottolenghi, Raffo e Grolman, em seu tratado de Técnica Quirurgica (1946), esclarecem que esta sutura foi ideada por Chassaignac, em 1851, permanecendo durante muitos anos no esquecimento. Entretanto, foi novamerte retomada em 1890 e difundida por Pozzi, Poncet, Zweifel, Marig e outros.

Bosch Arana, em 1937, apresenta minucioso estudo sôbre o assunto no seu livro de Técnica Quirurgica Sincronizada.

A revisão bibliográfica revela grande escassez de dados referentes a seu emprêgo em cirurgia veterinária. Excetuam-se observação de Moore (19:13), que faz uso da sutura intradérmica longitudinal no fechamento de incisão cutânea numa operação de cesariana em cadela; os casos relatados por Matrra (1947), referindo-se a cistotomia em cadela e a esofagotomias em cães, nos quais emprega a sutura intradérmica om zigue-zagnue para fechanıento da pelé e ainda as observações dêste mesmo A. (1918), estudando a técnica das incisões da perede ventral, na laparotomia do cão, onde cita a sutura intradérmica cm zigue-zague para o fechamento de 69 incisôes sôbre um total de 80.

A exiguidade de publicações referentes ao assunto, a falta de pormenores completos sôbre sua técnica nos compêndios de cirurgia veterinária e ao sucesso obtido nos casos observados durante vários anos de prática, nos animaram à pu. blicação dêste trabalho.

A sutura intradérmica executa-se por vários processos, segundo o tipo de pontos empregados, agrupando-se em duas categorias: 
]) sutura intradérmica de pontos separados;

2) sutura intradérmica contínua:
a) em zigue-zague,
b) em pontos transversais,
c) em pontos longitudinais.

A sutura intradérmica contínua em zigue-zague merece nossa preferência pelos resultados satisfatórios obtidos na prática.

Descreveremos êste tipo, mais freqüentemente usado por nós, fazendo-o, entretanto, com algumas modificaçōes que julgamos conveniente introduzir no método apresentado em livros clássicos de Técnica Cirúrgica Humana.

Técnica da sutura intradérmica em zigue-zague — E' uma sutura contínua reunindo as bordas cutâneas da incisão por meio de um fio duplo de algodão que atravsesa primeiro a epiderme e depois a derme de um e de outro lábio. Terminada a sutura, se vê apenas a passagem dos pontos na epiderme, permanecendo a incisão reduzida a uma linha, em cujas extremidades se encontram a entrada e a saida do fio.

Material -.- Emprega-se uma agulha lanceolada, de tamanho médio, com fundo oval fechado, ponteaguda. O fio de sutura utilizado é o de algodão preto, calibre n.: 16, de fabricação nacional, tipo comercial, engomado (carretel, marca Corrente).

Descrição do mélodo - A $5 \mathrm{~mm}$ da extremidade inicial da incisão introduz-se a agulha, e fazendo-a sair na derme pelo ângulo da incisão, puxam-se os 2 cabos do fio até atingir as proximidades do ponto de entrada da agulha, onde ficarão prêsos por pinça de Kocher. Com uma pinça "dente de rato" prende-se - lábio proximal da incisão que, desta maneira, mostrará ao cirurgião o plano de secção. Introduz-se a agulha obliquamente pela camada dérmica, formando com o eixo da ferida um ângulo de $45^{\circ}$, de modo a sair na epiderme distante $3 \mathrm{~mm}$ do ângulo inicial da incisão.

Virando-se a agulha, introduz-se de novo na epiderme a $2 \mathrm{~mm}$ do ponto de saída anterior; ao sair na luz da ferida a agulha será reintroduzida na derme do outro lado em sentido inverso e oblíquo ao anterior, puxando-a pelo lado oposto. Dêste modo se continua em zigue-zague até terminar a sutura na outra extremidade da incisão (fig. 1 ).

Ao chegar à extremidade final, passa-se a agulha pela borda interna do ângulo terminal da incisão, introduzindo-a na derme e retirando-a pela epiderme a uma distância de $5 \mathrm{~mm}$ desta extremidade, na direção do eixo da incisão. 
Uma vez terminada a sutura serão feitas trações com o fio prêso pelas extremidades, para ajustar perfeitamente os lábios da ferida. Finalmente, efetua-se um nó em roseta em cada extremidade da sutura, utilizando-se sòmente uma pinça de dissecção e o fio da sutura. Sua técnica, em 4 tempos, é simples, rápida e elegante. A ilustração em anexo traduz com fidelidade seus tempos de execução (figs.: 2,3 e 4 ).

Extração da sutura - Após 4-6 dias retira-se a sutura do seguinte modo: com auxílio de pinça de dissecção, puxa-se um pouco a extremidade do fio, pondo-se à vista uma pequena parte oculta abaixo da pele. Com tesoura introduzida abaixo da roseta, corta-se o fio. Uma vez seccionado, puxa-se pela outra extremidade e o fio sairá com facilidade.

\section{MATERIAL DE NOSSAS OBSERVAÇCES}

Nu serviço da Clínica Cirúrgica da Faculdade de Medicina Veterinária da Universidade de São Paulo, durante os anos de 1943 e 1949, e no primeiro semestre de 1950 , tivemos oportunidade de realizar 241 operações em animais das espécies canina e felina, adotando-se sistemàticamente a sutura intradérmica em zigue-zague para o fechamento das feridas. A técnica e material empregados descrevemos anteriormente.

Do total mencionado, 206 casos referem-se a operações em cães e 35 em gatos e estão assim distribuídos:

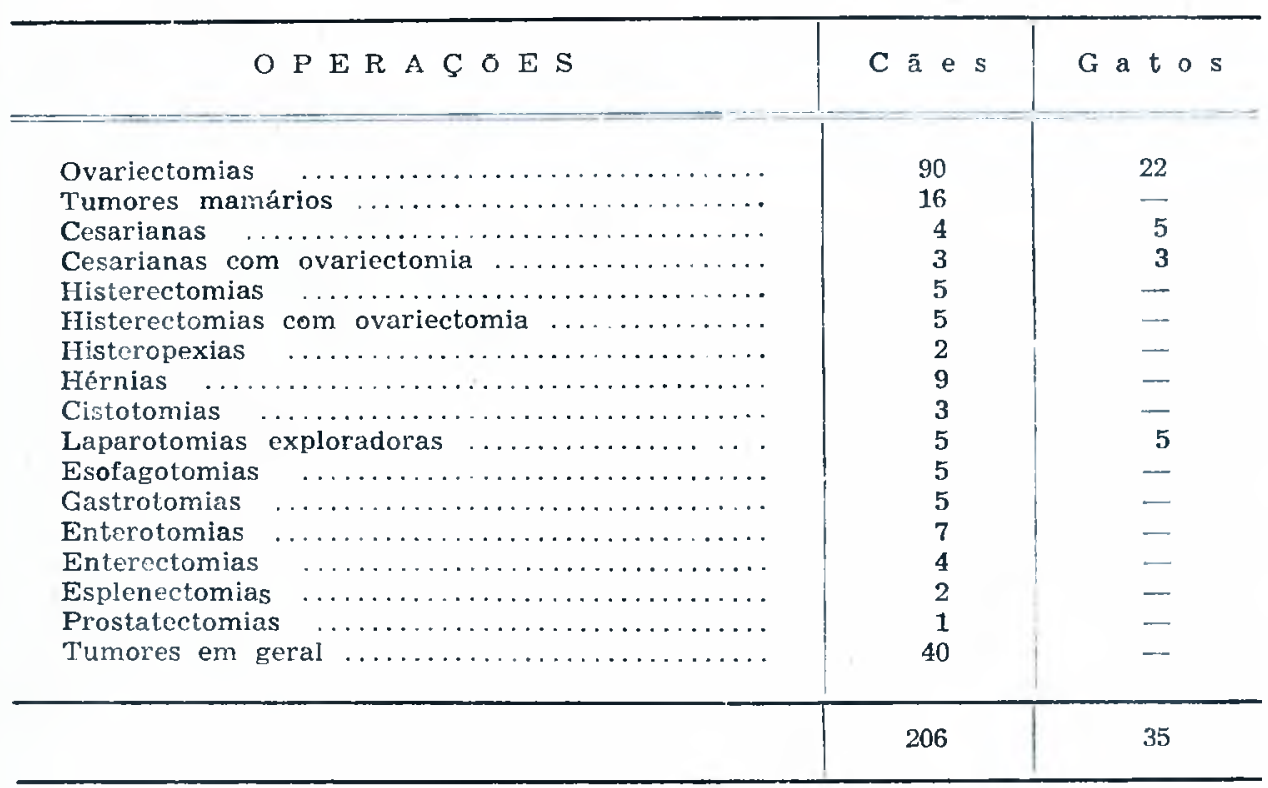


Segundo nossas observações podemos apresentar as seguintes conclusões:

1) O fechamento da incisão é tão seguro que a mobilidade dos animais operados não o compromete;

2) os lábios da ferida operatória não ficam invertidos, não deixam espaços mortos de permeio, determinando, por conseguinte, coaptação perfeita e cicatrização "per primam";

3) a cicatriz é linear e nāo acompanhada de marcas ou sinais laterais, como ocorre em processus por grampos;

4) a retirada dos pontos, feita entre o $49^{\circ}$ e $6 .^{\circ}$ dia, ć indolor, de execuçāo fácil, dispensando instrumental apropriado;

5) o material empregado nesta sutura é de fácil aquisição e de baixo custo;

6) o tempo, para execuçäo, um dos inconvenientes apontados por alguns autores, pode ser reduzido pela habilidade do cirurgião.

\section{RESUMO}

Após considerações sucintas sôbre os processos de síntese da pele os autores fazem um estudo sôbre a sutura intradérmica.

Passam em revista a bibliografia que puderam consultar sôbre o assunto e citam os vários tipos de sutura intradérmica ideados pelos autores.

A seguir estudam a sutura intradérmica em zigue-zague, descrevendo sua técnica, o material, o método e a extração da sutura.

Apresentam quadro com 241 operaçōes praticadas em animais, sendo $206 \mathrm{em}$ cães e $35 \mathrm{em}$ gatos, usando sistemàticamente a sutura em aprêço no fechamento das incisões cutâneas. Baseados nas observações discriminadas e realizadas durante cêrca de três anos de prática, concluem apontando as vantagens que decor. rem de seu emprêgo.

\section{SUMMARY}

After short considerations about the methods of closing wounds of the skin, the authors make a study about the subcuticular suture.

Revising the bibliography which they were able to consult upon the subject they quote various methods subcuticular suture conceived by the authors. 
Immediately after they study the zig-zag subcuticular suture and describe the technique, the material, the method and the removing of the suture.

They presente table with 24.1 operations performed on animals, 206 heing on dogs and 35 on cats, using systematically the indicated suture to the closing up of the cutaneous incisions. Based on discriminating observations carried out during three years of practice, they conclude by pointing out the advantages result ing of its use.

\section{CITACAO BIBLIOGRAFICA}

Bosch Arana, G. - 1937 'Técnica quirurgica sincronizada. 1 :398-413. 1Bs. Aires, Aniceto López

Christmann, E. F. - Ottotenght, C. E. - Raffo, .J. M. - Grolman, G. von - Técnica Quirurgica. 1:466-78. 6." ed. Bs. Aires, "Ll Ateneo"

Matera, E. A. - 1947 - Calculose vesical em cadela. (Cistotornia pré-púbica). Rev. Soc. Paul. Med. Vet., 8(1):37-41

Matera, E. A. - 1947 - Contribuição para a técnica da esofagutomia em cão. Rev. Soc. Paul. Med. Vet., 8(1):20-30

Matera, E. A. - 1948 - Contribuição para a cirurgia abdominal do cão. (Estudo e técnica das incisões da parede ventral). Tese. S. Paulo, Grífica S. José

Monnerro, A. e colab. - 1936 - Técnica cirírgica. (Preliminares, parte geral). $286-317$. R. de Janeiro, Liv. Francisco Alves

Moore, G R. - 1943 - Observations on cesarean section in the dog. Vet. Med., 38:103-6 
E. A. Matera a $\Lambda, V$. Stopiglia Sutura intradérmica na cirurgia

Estampa

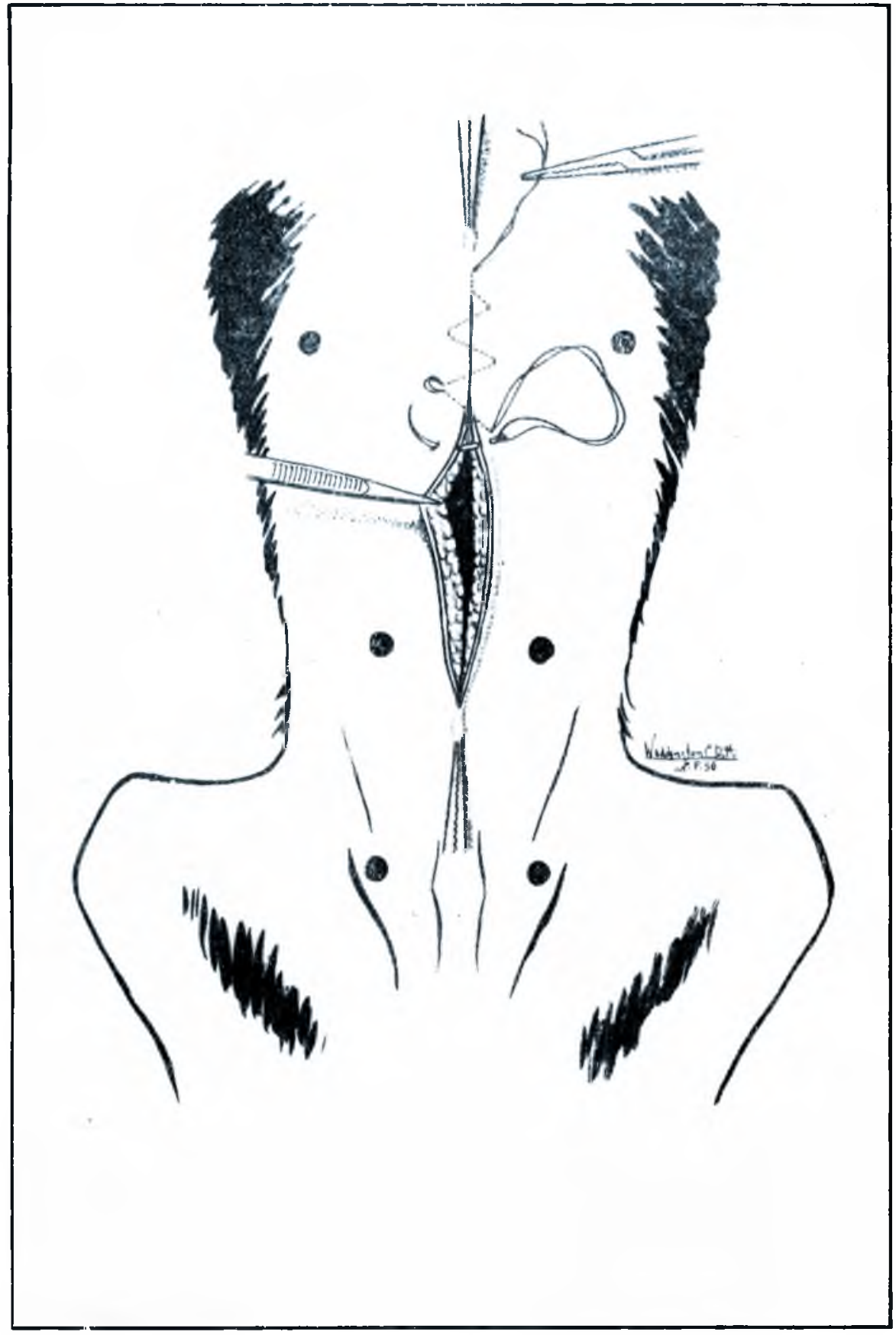

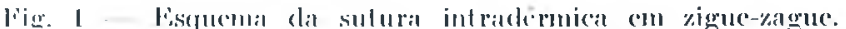




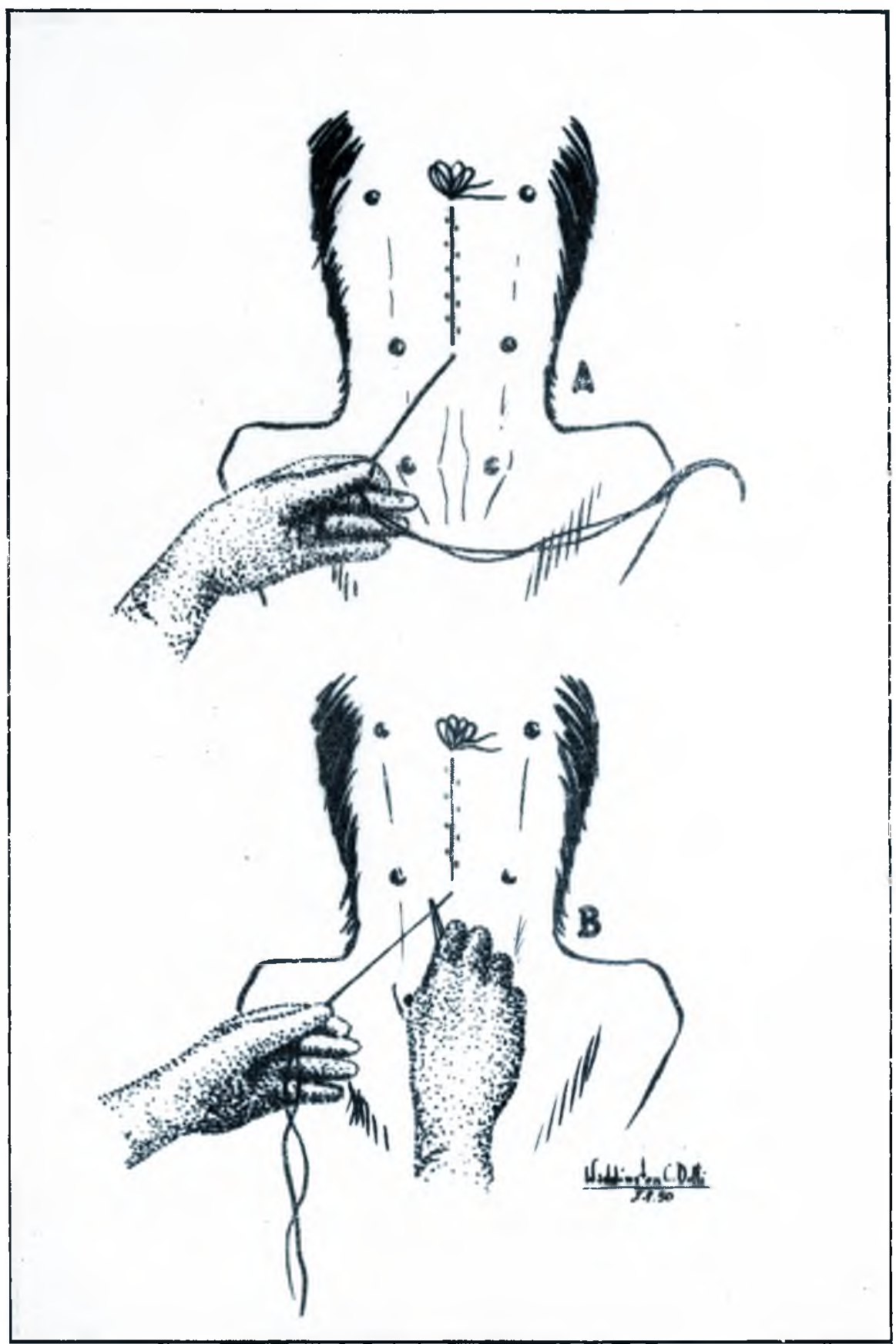

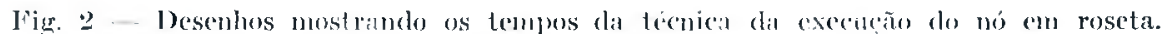


F.stampa III

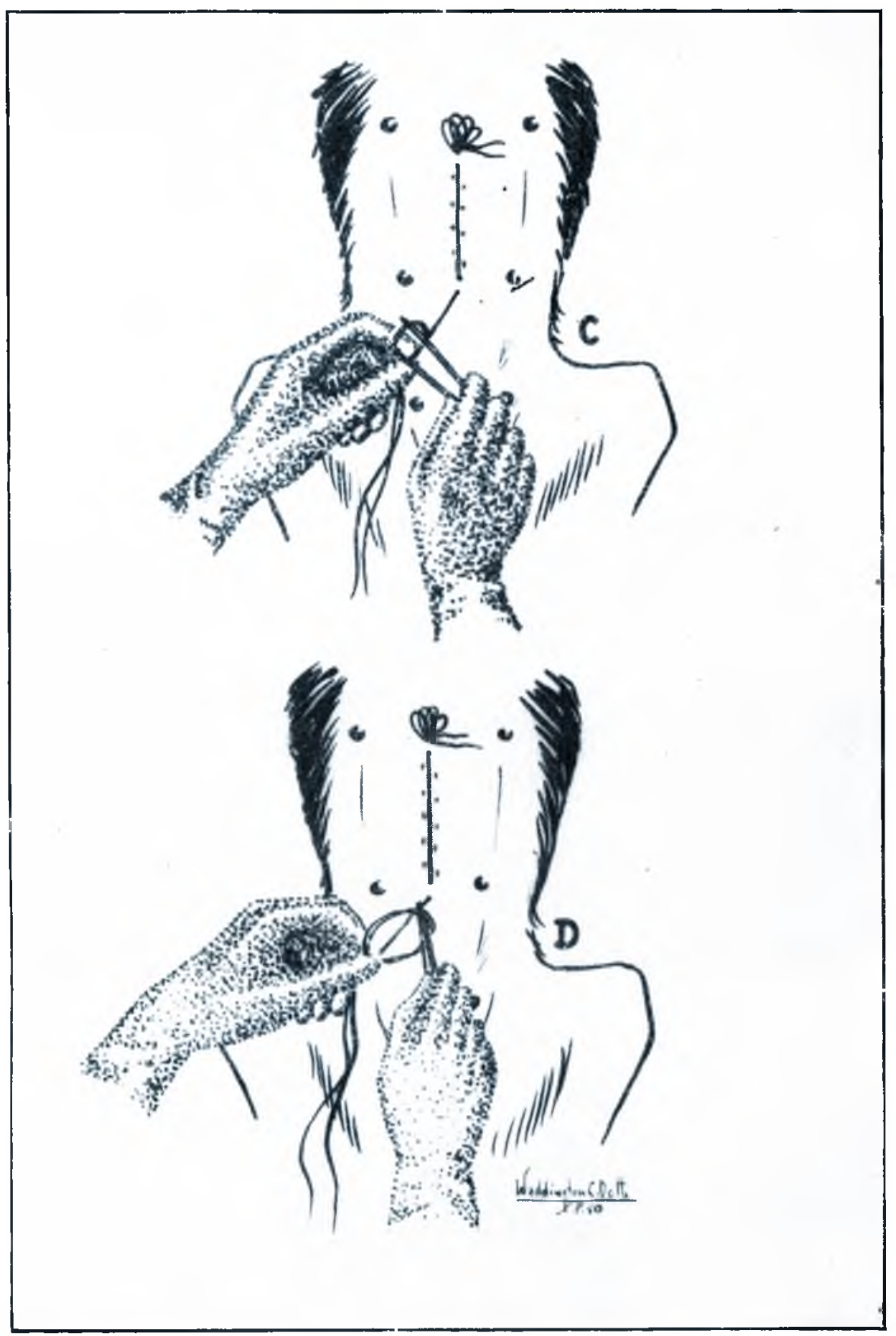

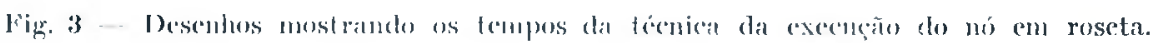




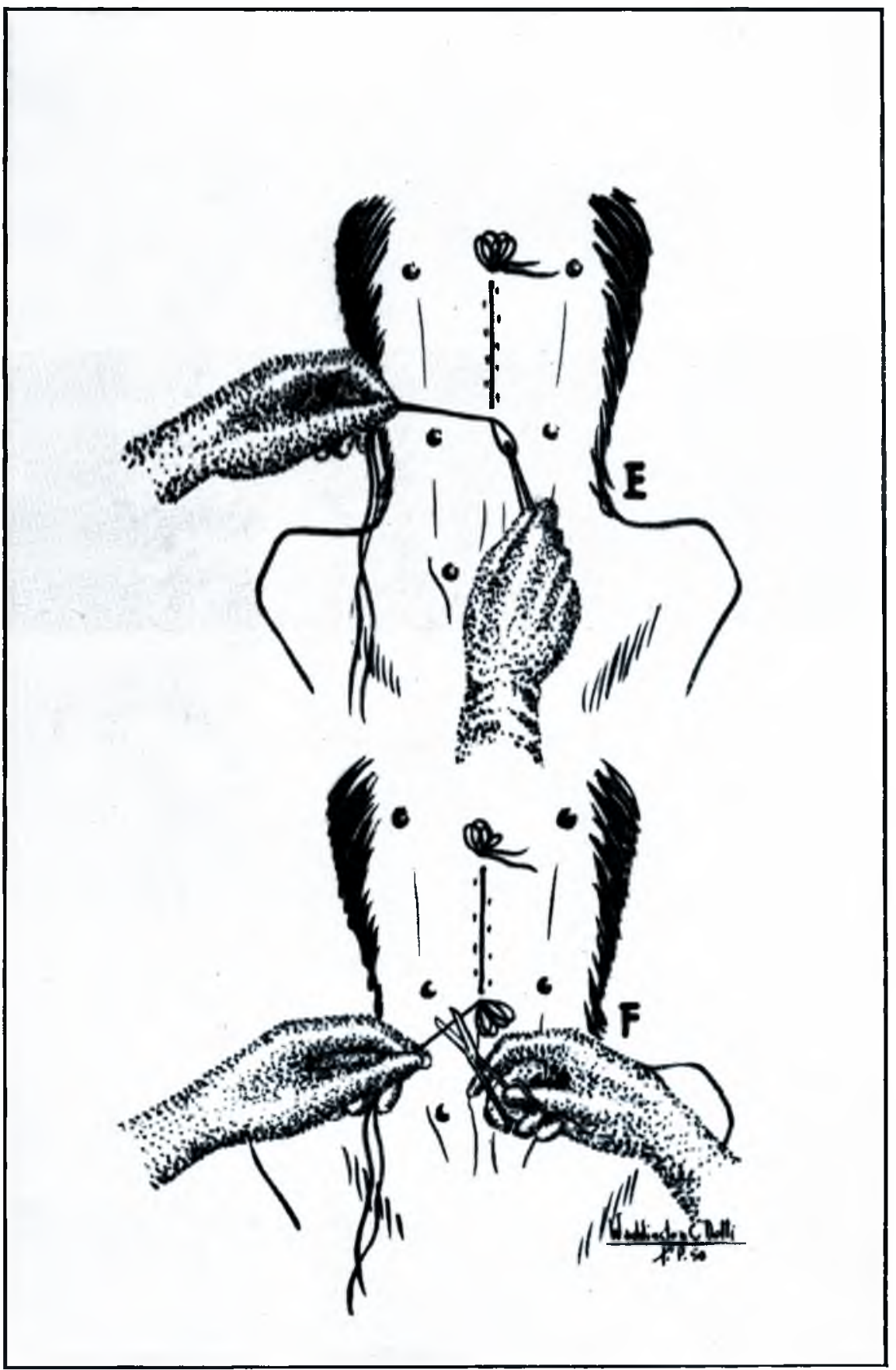

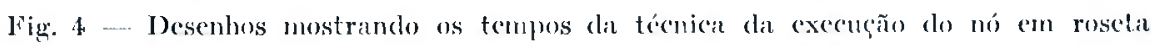

